\title{
A utilização do corpus de culinária da plataforma CoMET como base para elaboração de atividades lúdico-pedagógicas para o ensino de competências profissionais do tradutor
}

\author{
Talita Serpa \\ UNESP/S. J. Rio Preto (PPGEL) \\ talitasrp82@gmail.com
}

Eduardo Batista da Silva Universidade Estadual de Goiás eduardobatistadasilva@gmail.com

Isadora Rogério União das Faculdades dos Grandes Lagos (Grad) isarogerio@terra.com.br

Brenda Espinha Martins União das Faculdades dos Grandes Lagos (Grad) espinhab@gmail.com

\section{Resumo}

Com o crescente desenvolvimento dos Estudos da Tradução, principalmente aqueles voltados ao uso de corpora para a aquisição de competências indispensáveis à formação profissional, tornou-se clara a necessidade de se criar estratégias para que aprendizes aperfeiçoem seus saberes, em especial no tocante ao processo tradutório de linguagens de especialidade. Assim, partindo dessas premissas, procurou-se elaborar atividades lúdico-pedagógicas que possam ser inseridas na disciplina Prática de Tradução I, presente nos anos iniciais das grades curriculares dos cursos de graduação brasileiros. Essas ações se pautam na utilização dos dados do subcorpus de culinária do Cortrad dentro Projeto Corpus Multilíngue para Ensino e Tradução (CoMET) na direção português $\leftrightarrow$ inglês. Para tanto, foram utilizadas a Linguística de Corpus (BAKER, 1995; BERBER SARDINHA, 2004; OLIVEIRA, 2009; O'KEEFFE; MCCARTHY, 2010; SERPA, ROCHA, 2016); os Estudos da Tradução Baseados em Corpus (DAYRELL, 2015), 
além das investigações sobre Competências Tradutórias (PICCIONI; PORTRANDOLFO, 2017; SERPA, 2017) e sobre Educação Lúdica (LIBÂNEO, 2005; D’ÁVILA, 2007; ALMEIDA, 2016). Por conseguinte, foram elencados três verbos e três substantivos de uso mais frequente e construídas duas diferentes propostas, a saber: Scrabble e Imagem e ação; com objetivo de explorar o ensino de competências por meio de dados de corpora.

Palavras-chave: Linguística de Corpus. Competências Tradutórias. Atividades de Ensino Lúdico-Pedagógicas. Projeto CoMET. Culinária.

\section{Resumo}

With the development of Translation Studies, mainly those researches focused on the use of corpora for the acquisition of professional competences, it was necessary to create strategies so that learners improve their knowledge, especially related to translational processes for specialized languages. Having this in mind, we intend to develop playful and pedagogical activities for the discipline Translation Practice I, which is common in Brazilian undergraduate syllabuses. Such actions are guided by the data of the Portuguese $\leftrightarrow$ English culinary subcorpus in Cortrad (CoMET Project). To do so, we base our investigations on Corpus Linguistics (BAKER, 1995; BERBER SARDINHA, 2004; OLIVEIRA, 2009; O'KEEFFE; MCCARTHY, 2010; SERPA, ROCHA, 2016); Corpus Based Translation Studies (DAYRELL, 2015), Translational Competences Theories (PICCIONI; PORTRANDOLFO, 2017; SERPA, 2017) and on Ludic Education (LIBÂNEO, 2005; D’ÁVILA, 2007; ALMEIDA, 2016). Therefore, we verified three most frequent verbs and nouns and built two different games, namely: Scrabble and image and action; with the aim of exploring the teaching of competences through corpora data.

Keywords: Corpus Linguistics. Translational Competences. Ludic pedagogical Teaching Activities. CoMET Project. Culinary.

\section{Introdução}

O Estudo da Tradução, por meio de sua associação com premissas advindas da Linguística de Corpus (doravante LC), é uma área que se expandiu nas últimas décadas, tendo como expoentes as professoras Baker (2000), Olohan (2004) e Laviosa (2002), entre outros pesquisadores. No entanto, a utilização de corpora eletrônicos para o desenvolvimento de competências e habilidades cabíveis aos profissionais da tradução tornou-se pauta de estudos e de análises apenas muito recentemente (BERBER SARDINHA, 2010; ALVES, TAGNIN, 2010), o que enfatiza a necessidade 
de se explorar formas práticas e teóricas de elaborar mecanismos que facilitem o processo de ensino-aprendizagem dentro da construção dos princípios de uma emergente Pedagogia da Tradução Baseada em Corpus.

Assim, o grupo PACTE (Processo de Aquisição da Competência Tradutória e Avaliação), da Universidade Autônoma de Barcelona, destacase no desenvolvimento de diversos trabalhos sobre ensino de competências tradutórias e procura definir este conceito para destacar a diferença da formação deste profissional em relação às demais ocupações que utilizam a Linguagem e a Comunicação como instrumento/ferramenta (PACTE, 2015, 2014, 2011a, 2011b).

Por conseguinte, em nossa pesquisa, objetivamos: 1) atrelar as teorias sobre Tradução e LC a uma exploração pedagógica do desenvolvimento de atividades que fomentem a formação de competências, a saber: comunicativa, extralinguística, instrumental e estratégica; e 2) elaborar jogos didáticos a partir da seleção de itens lexicais no corpus paralelo português $\leftrightarrow$ inglês do Projeto CoMET ${ }^{1}$, com o intuito de promover a formação inicial de tradutores no contexto da disciplina Prática de Tradução $\mathrm{I}^{2}$, de modo que seja possível dialogar com estudos advindos da Pedagogia, no que diz respeito à ludicidade (MASSA, 2015).

Partimos da hipótese de que, uma vez que o Projeto CoMET apresenta um compilado de traduções reais, sua utilização como fonte de dados de corpora pode fornecer subsídios para o desenvolvimento de ações educativas estruturadas no formato de dois jogos: Scrabble e Imagem e ação.

Além de fomentarmos a utilização do instrumental, da teorização e de, pelo menos um dos bancos de dados da LC disponibilizados no Brasil, ainda realizamos um recorte de seu uso para fins de ensino-aprendizagem, procurando vinculá-los ao uso da ludicidade para fins de profissionalização, o que vem sendo discutido dentro do panorama pedagógico (LIBÂNEO, 2005).

\footnotetext{
${ }^{1}$ Disponível em: http://comet.fflch.usp.br/

${ }^{2}$ A disciplina Prática de Tradução I é oferecida nos anos iniciais das seguintes graduações: Universidade de Brasília, Universidade Estadual Paulista, Pontifícia Universidade Católica do Rio de Janeiro, Pontifícia Universidade Católica de São Paulo, Universidade Federal do Rio Grande do Sul, Universidade Federal de Ouro Preto, Universidade Federal de Uberlândia, entre outras.
} 


\section{Linguística de Corpus}

A LC encara a linguagem como um fenômeno social e sua análise depende da comunicação, mais especificamente de seus atos concretos, textos reais, com o objetivo de buscar "significado onde este é negociado, ou seja, no discurso" (OLIVEIRA, 2009, p. 49). Sua análise depende do auxílio de programas de computadores específicos, que serão trabalhados posteriormente, para ser realizada a fim de extrair as evidências linguísticas do conjunto de textos analisado.

O princípio de corpus compreende, pois, qualquer coleção de texto em meio digital ou não, organizado de acordo com determinados padrões. A definição foi sofrendo mudanças e passou a significar uma coleção de textos em formato eletrônico, passíveis de serem analisados automática ou semiautomaticamente (SERPA, ROCHA, 2016, p. 94).

Tende a nos conduzir “(...) a reflexões além do léxico ou da gramática ao aplicar suas técnicas para outras demandas, umas respondidas com maior facilidade por análises computacionais do que outras" (O'KEEFFE; MCCARTHY, 2010, p. 7, tradução nossa ${ }^{3}$ ), como, por exemplo, o fato de que os números observados nas análises servem como uma base de frequências. Isso significa que esses resultados não mostram nada além de números que necessitam da interpretação por parte de pesquisadores da área, sendo estes os verdadeiros responsáveis para apontar novas descrições linguísticas e, até mesmo, de propor novas formas de se enxergar teorias (OLIVEIRA, 2009).

\subsection{Estudos de corpora na Tradução}

Por meio das funcionalidades e das facilidades do uso de corpora nos Estudos da Tradução, pesquisadores passaram a ter os recursos necessários para pesquisar as particularidades de cada texto traduzido. Isso fica claro na afirmação de Baker (1993, p. 235, tradução de Dayrell, 2015, p. 89):

\footnotetext{
${ }^{3}$ That is, CL leads to insights beyond the realms of lexis or grammar by applying its techniques to other questions, some more easily answered by computational analysis than others.
} 
Grandes corpora oferecem aos teóricos de tradução uma oportunidade única para observar seu objeto de estudo e explorar o que o faz diferente de outros objetos de estudo, tais como a linguagem em geral ou mesmo qualquer outra forma de interação cultural. Eles possibilitam explorar também, em uma escala muito maior do que já foi possível até então, os princípios que governam o comportamento tradutório e as limitações sob os quais ele opera. Aí sim estão os objetivos de qualquer investigação teórica: definir e explicar o seu objeto de estudo.

A partir dos corpora, o Estudo da Tradução passou a ter por objetivo principal tanto entender quanto explicar o processo tradutório, além de analisar a estrutura dos textos traduzidos, o que foi amparado pelo surgimento da área Estudos da Tradução Baseados em Corpus.

\subsubsection{O Projeto CoMET}

Organizado por Tagnin, pesquisadora nas áreas de Tradução Técnica, Tradução Literária, Idiomaticidade e convencionalidade Terminologia, Ensino e Aprendizagem com Corpus e LC, o Projeto CoMET foi, de acordo com sua plataforma oficial,

[...] desenvolvido junto ao Departamento de Letras Modernas da Faculdade de Filosofia, Letras e Ciências Humanas da Universidade de São Paulo [...] que tem por objetivo servir de suporte a pesquisas linguísticas, principalmente nas áreas de Tradução, Terminologia e Ensino e Aprendizagem de Línguas (COMET, 2018).

O CoMET é composto por três subcorpora, sendo eles o Corpus Técnico-Científico (CorTec), o Corpus Multilíngue de Aprendizes (CoMAprend) e o Corpus de Tradução (CorTrad). Apesar de cada um deles ter um direcionamento para a linguagem técnica, ensino de língua estrangeira ou tradução, todos possuem base textual semelhante.

Em nossa investigação, nos pautamos no CorTrad, um corpus aberto em constante ampliação. Surgido de uma parceria entre o CoMET, a Linguateca e o NILC (Núcleo Interinstitucional de Linguística 
Computacional), iniciada em maio de 2008. Sua divisão é feita em três partes, ou três subcorpora: "Literário (por ora, contos australianos e canadenses); Técnico-científico (por ora, culinária) e Jornalístico (por ora, divulgação científica)" (COMET, 2018).

\section{Competências tradutórias e ensino de tradução}

No âmbito educacional, a concepção de competência é utilizada como intercorrência para a capacidade, a habilidade e a aptidão, a potencialidade ou o conhecimento; é tida, inclusive, como aquilo que proporciona ao aprendiz facear e regular de maneira adequada um grupo de trabalhos. Assim, podemos afirmar que a

(...) competência será um constructo teórico que se supõe como uma construção pessoal, singular, específica de cada um. É única e pertence, exclusivamente, à pessoa, exprimindo-se pela adequação de um indivíduo a uma situação (DIAS, 2010, p. 74).

A partir desse conceito relacionado à área da educação, abordamos sua concepção na área da Tradução. No decorrer dos últimos trinta anos, foram desenvolvidas teorias próprias nos Estudos da Tradução e também houve uma grande expansão da atividade tradutória, tornando a formação acadêmica do tradutor algo de maior valor.

Sendo assim, a necessidade de se pensar na formação de qualidade desses futuros profissionais tornou-se maior. Portanto, é possível dizer que

(n)as décadas de 1970 e 1980, quando o número de cursos de tradução começou a aumentar, até os dias de hoje, os avanços da tecnologia e das reflexões teóricas - tanto na área da educação como nas dos estudos da tradução - impuseram transformações significativas ao ensino da tradução. (MARTINS, 2006, p. 28)

Uma dessas transformações foi, justamente, a inserção das competências no ensino e a criação do que chamamos de competências tradutórias, também denominadas CTs. Segundo Hurtado Albir (2000), as 
CTs são um sistema subjacente de conhecimentos, habilidades e atitudes que se mostram necessárias para o ato de traduzir e é formada por um grupo de subcompetências.

Os autores dividem seu modelo de CTs em seis subcompetências: a competência comunicativa nas duas línguas, a competência extralinguística, a de transferência, a instrumental e profissional, a psicofisiológica e a competência estratégica. Entretanto, apesar da divisão feita, os teóricos afirmam que

Todas essas subcompetências funcionam de maneira imbricada para constituir a competência tradutória e se integram em todo ato de traduzir. Entre elas existem relações, hierarquias e variações. A competição estratégica pelo papel regulatório e compensatório das demais subcompetências ocupa um lugar central na interconexão, já que corrige deficiências nelas e serve para resolver problemas. (PACTE, 2001, p. 40, tradução nossa ${ }^{4}$ )

O grupo define competência comunicativa nas duas línguas como um sistema subjacente de conhecimentos e de habilidades que são necessários para a comunicação linguística. Essa competência engloba a compreensão da língua de partida e a produção na língua de chegada. A competência extralinguística é definida como sendo o conjunto de conhecimentos acerca do mundo em geral e de âmbitos particulares.

Já a competência de transferência é mencionada pelos autores como sendo a capacidade de recorrer ao processo de transferência desde o texto original até a elaboração do texto final. A instrumental e profissional são os conhecimentos e as habilidades relacionados com o exercício da tradução profissional.

As duas últimas competências mencionadas no texto são a competência psicofisiológica - que é a habilidade de aplicar recursos

\footnotetext{
${ }^{4}$ Todas estas subcompetencias funcionan de manera imbricada para constituir la competencia traductora y se integran en todo acto de traducir. Entre ellas existen relaciones, jararquias y variaciones. En la interrelación ocupa un lugar central la competencia estratégica por el papel regulador y compensador del resto de subcompetencias, ya que subsana deficiencias en ellas y sirve para resolver problemas.
} 
psicomotores, cognitivos e atitudinais nas traduções - e a competência estratégica - que nada mais é do que os procedimentos individuais que são utilizados para resolver os problemas que podem ocorrer durante o processo de tradução.

Há um processo de aquisição dessas CTs que é dinâmico, ou seja, a reconstrução e o desenvolvimento das seis subcompetências. Tendo isso em vista, podemos afirmar que a aquisição das CTs não difere de nenhum outro processo de aprendizagem: necessita de um conhecimento inicial que se desenvolverá para um conhecimento especializado. É um processo diligente e cíclico, com sucessivas reestruturações, e requer estratégias de aprendizagem.

\subsection{Competências e corpora}

É muito provável que, ao pensarmos em corpora e competências, em um primeiro momento, imaginemos duas linhas paralelas que não se encontram, que não possuem ligação. No entanto, esses conceitos estão intimamente associados, uma vez que partimos do pressuposto de que foram necessárias competências para o desenvolvimento de um corpus, independentemente se este for técnico, voltado para o ensino ou para a tradução. Essas competências, a nosso ver, dialogam com as pontuadas no tópico anterior.

Além disso, "se estudar a competência da tradução apresenta vários desafios, é ainda mais complicado investigar como essa competência é adquirida" (PICCIONI; PORTRANDOLFO, 2017, p. 87, tradução nossa ${ }^{5}$ ). Isso se deve ao fato de, como mencionado, as competências não se desenvolverem isoladamente, mas sim de forma conjunta. Para exemplificação, pensemos no caso do CoMET, a plataforma base para a realização do trabalho: para utilizá-lo, precisamos desenvolver as competências comunicativas, extralinguísticas, as instrumentais e as estratégicas, caso contrário, sua utilização se torna demasiado complexa.

As competências comunicativas são necessárias para termos ciência de como determinadas palavras são expressadas e como são colocadas em ordem, isto é, qual a combinatória feita dentro de contextos específicos.

\footnotetext{
${ }^{5}$ En efecto, si estudiar la competencia traductora plantea varios desafíos, resulta aún más complicado investigar cómo se adquiere dicha competencia.
} 
As competências extralinguísticas abrangem aquilo que se encontra além da realidade da linguagem, os elementos culturais. Em nosso trabalho, esses elementos englobam a culinária, ou seja, o preparo dos alimentos para consumo. Assim como em outras áreas, a culinária apresenta diversos elementos existentes em determinadas culturas, e as competências extralinguísticas são responsáveis por tangenciar, aqui, as competências comunicativas.

No entanto, muito embora o conhecimento em relação às palavras, suas possíveis combinatórias e seus significados em relação a contextos diferenciados seja necessário, ele, por si só, não é suficiente. Há, ainda, a necessidade de desenvolvimento da competência instrumental, também conhecida como tecnológica ou técnica, uma vez que precisamos saber lidar com o instrumental tecnológico, isto é o corpus e a plataforma digitalizada em questão.

Por fim, a competência de saberes tradutórios, ou competência estratégica, também é necessária ao longo desse processo. Dentro das reflexões abordadas nesse momento estão: como os tradutores traduzem mais e, por conta disso, utilizam dadas palavras com maior recorrência, consequentemente compondo dados de corpora. A partir dessa competência, em paralelo às demais, podemos realizar uma observação, uma verificação de diversas informações por meio do uso do corpus, seja este qual for, dentro da plataforma digital.

Mas muito além de estudar como sua aquisição acontece, é possível inserir esse conteúdo como base metodológica do ensino e aprendizagem dentro do ambiente educacional da Tradução. E é justamente por isso que diversos “(...) cursos estão preocupados em apresentar aos alunos vários tipos de ferramentas, equipamentos e programas para ampará-los em suas tarefas" (SERPA, 2017, p. 137), uma vez que a até o momento a “(...) utilização dos recursos da Linguística de Corpus para a didática dos cursos de Tradução concentra-se, de modo geral, no ensino das línguas envolvidas no processo tradutório" (p. 139).

Assim, ainda de acordo com Serpa (2017), uma das formas de se desenvolver a utilização de corpora durante o período da formação inicial do tradutor com o intuito de submetê-lo a um processo constante de aquisição de competência é, justamente, transformar o professor no mediador entre o conhecimento e os alunos, a fim de que estes se tornem capazes de tomarem a iniciativa de controlar o seu próprio aprendizado, quando munidos dos conceitos e das ferramentas adequadas. 


\subsection{O ensino de competências tradutórias por meio do uso de atividades lúdico-didáticas pautadas em dados de corpora}

Competência, dentro do ambiente escolar, como previamente mencionado, é uma noção de todos os saberes: entre eles, o chamado aprender a aprender é o privilegiado. Portanto, nesse sentido, podemos afirmar que as competências tradutórias se tornaram de suma importância no âmbito pedagógico, já que os estudantes de tradução, assim como todos aqueles que estudam uma língua estrangeira, "necessitam adquirir uma série de habilidades e competências por meio das quais terão que transmitir e entender a intencionalidade em um contexto adequado de uma forma comunicativa" (GUTIÉRREZ, 2012. p. 326).

Sendo assim, se considerarmos Tradução “(...) como uma atividade de mediação que envolve elementos orais e escritos, componentes linguísticos, extralinguísticos, comunicativos, bem como aspectos relacionados à realidade concreta na qual o tradutor é formado e opera" (MORELLI, 2008, p. 80), tornou-se necessário acrescentar essas competências e habilidades na grade da disciplina Prática de Tradução I dos cursos de formação de tradutores.

Por conseguinte, ao fazer uso de recursos de corpora em atividades práticas que tenham o intuito de desenvolver as competências tradutórias exemplificadas pelo Grupo PACTE pode ser algo valioso no contexto de ensino-aprendizagem. Dessa forma, para dinamizar e tornar mais fácil tanto a compreensão quanto a aquisição de vocabulário dos quais os tradutores podem fazer uso em seus futuros trabalhos, procuramos elaborar nesse trabalho alguns exemplos de atividades lúdicas que possam auxiliar no desenvolvimento das competências tradutórias.

Na obra Educação lúdica: teorias e práticas (2013), Almeida considera que a ludicidade mobiliza atos funcionais, relacionando-os ao prazer e à satisfação. Nesse sentido, estabelecem-se as interações entre o lúdico, o brinquedo, a brincadeira, o jogo no processo de interpretar o mundo e de agir nele (p.16).

No âmbito do ensino superior de competências profissionais, autores como Libâneo (2005) nos dão as bases para ancorar as atividades nos princípios do lúdico. $\mathrm{O}$ autor sugere que as metodologias tendem a se concentrar em teorias que priorizam a razão e a ciência em detrimento da imaginação e da liberdade, "à medida que a razão, institui-se como instrumento de dominação sobre os seres humanos" (p. 25). 
Para D’Ávila (2007), é necessário superar esse histórico e ultrapassar os limites impostos à brincadeira no ambiente infantil e compreender que jogos dialogam diretamente com a realidade, pois estruturam os fatos de maneira a dar vazão à imaginação e ao conjunto de escolhas e opções relativas à afetividade, à liberdade e à autonomia, que são indispensáveis ao trabalho de qualquer profissional.

\section{Material e método}

Com o auxílio do CorTrad, da plataforma CoMET, foram selecionadas dez palavras que aparecem com maior frequência em textos do gênero culinário. Essas palavras foram separadas em dois grupos, com três verbos e três substantivos, respectivamente. No primeiro grupo temos os verbos "bata", "sirva", "misture", todos no imperativo, característica do gênero textual em questão. E, no segundo grupo, os substantivos selecionados foram "pitada", "copo/xícara", "colher", que representam as medidas em receitas.

Levando em consideração os benefícios que atividades lúdicas podem oferecer ao ensino, buscamos elaborar uma dinâmica que contribua no reconhecimento da linguagem, do instrumental da LC, bem como de fatores socioculturais por parte daqueles que visam à formação de tradutor. Assim sendo, escolhemos alguns jogos e atividades, a saber:

a) Scrabble; e

b) Imagem e ação.

\subsection{Seleção dos dados do subcorpus de culinária}

Para a seleção das palavras, utilizamos o gerador de listas do CorTec, posteriormente, o recurso de busca do CorTrad. Além disso, escolhemos a opção de "concordância em contexto" e a tradução revisada em vez da primeira tradução.

"Misture" é um dos primeiros verbos a aparecer na lista de frequência; aparece na quinquagésima primeira posição $\left(51^{\mathrm{a}}\right)$ da lista com 822 aparições. Foi traduzido para a língua inglesa de mais de uma forma, a saber: combine, mix e stir, como pode ser analisado no quadro 1: 


\section{Quadro 1. Concordância para o item lexical misture}

\begin{tabular}{|l|l|}
\hline \multicolumn{1}{|c|}{ Original } & \multicolumn{1}{|c|}{ Tradução revisada } \\
\hline $\begin{array}{l}\text { Numa tigelinha, misture o pão, o } \\
\text { restante do alho e do parmesão, a } \\
\text { salsinha, sal e pimenta, regue com } \\
\text { azeite e esfarele até obter uma farofa } \\
\text { soltinha }\end{array}$ & $\begin{array}{l}\text { In a small bowl, combine breadcrumbs, } \\
\text { remaining garlic and Parmesan, } \\
\text { parsley, salt and pepper; drizzle with } \\
\text { olive oil and rub, with the tip of your } \\
\text { fingers, until the mixture resembles } \\
\text { coarse breadcrumbs. }\end{array}$ \\
\hline $\begin{array}{l}\text { Misture a água, o açúcar e a glicose } \\
\text { numa panelinha, aqueça, conte 5ix } 5 \\
\text { minutos a partir da fervura, junte a } \\
\text { verbena, retire do fogo e deixe em } \\
\text { infusão por 5 minutos }\end{array}$ & $\begin{array}{l}\text { Mix water, sugar and corn syrup in a } \\
\text { small pan, bring to a boil and, 5 } \\
\text { minutes after boiling, add verbena } \\
\text { leaves, remove from heat and let sit for } \\
5 \text { minutes". }\end{array}$ \\
\hline $\begin{array}{l}\text { Aqueça a água e o açúcar numa } \\
\text { panelinha e misture até dissolver. }\end{array}$ & $\begin{array}{l}\text { Heat water and sugar in a small } \\
\text { saucepan, stir until dissolved. }\end{array}$ \\
\hline
\end{tabular}

Fonte: http://comet.fflch.usp.br/ (2018)

Em seguida, temos o verbo "bata" na septuagésima terceira posição $\left(73^{\mathrm{a}}\right)$, totalizando 521 ocorrências no subcorpus. Assim como no caso de "misture", não existe uma tradução única para "bata"; os resultados mostram traduções muito semelhantes aos do verbo anterior, entre elas combine, beat, stir e mix (quadro 2).

Por fim, temos "sirva" na sexagésima quinta posição $\left(65^{\mathrm{a}}\right)$, com um total de 599 aparições. Apesar de ser possível encontrar mais aparições que "bata", "retire" e "cozinhe", ele foi deixado ao final por ter uma única tradução em todos os 166 trechos do CorTrad, ao contrário dos demais verbos selecionados. (quadro 3). 
A utilização do corpus de culinária da plataforma CoMET...

\section{Quadro 2. Concordância para o item lexical bata}

\begin{tabular}{|c|c|}
\hline Original & Tradução revisada \\
\hline $\begin{array}{l}\text { Bata no liquidificador o iogurte, o leite, } \\
\text { a banana (guarde umas rodelinhas para } \\
\text { decorar), o açúcar, a água de flor de } \\
\text { laranjeira e metade do gelo. }\end{array}$ & $\begin{array}{l}\text { Combine yogurt, milk, banana (set } \\
\text { aside a few slices to garnish), sugar, } \\
\text { orange flower water, and half the ice } \\
\text { cubes in a blender. }\end{array}$ \\
\hline $\begin{array}{l}\text { Bata por mais } 1 \text { minuto para a massa } \\
\text { encorpar e desligue a batedeira. }\end{array}$ & $\begin{array}{l}\text { Beat for another minute to obtain a } \\
\text { more consistent batter; switch off the } \\
\text { mixer. }\end{array}$ \\
\hline $\begin{array}{l}\text { Bata sem parar com um batedor de } \\
\text { arame por uns } 5 \text { minutos, até conseguir } \\
\text { um creme bem fofo e encorpado (se } \\
\text { levantar o batedor e deixar o creme cair, } \\
\text { o desenho que se formar deverá } \\
\text { demorar um pouco para desaparecer). }\end{array}$ & $\begin{array}{l}\text { Stir constantly with a wire whisk for } \\
\text { about } 5 \text { minutes, until a firm and very } \\
\text { fluffy cream is obtained (when you lift } \\
\text { out the wire whisk, the mixture trails } \\
\text { back onto the surface of the remaining } \\
\text { mixture to make a ribbon that holds its } \\
\text { shape). }\end{array}$ \\
\hline $\begin{array}{l}\text { Bata o capim-limão e metade da água } \\
\text { no liquidificador até triturar a parte fina } \\
\text { e macia das folhas, sobrando só os } \\
\text { talinhos duros. }\end{array}$ & $\begin{array}{l}\text { Mix lemongrass and half the water in a } \\
\text { blender until slender soft parts of the } \\
\text { leaves are thinly chopped and only } \\
\text { chunked white parts remain. }\end{array}$ \\
\hline
\end{tabular}

Fonte: http://comet.fflch.usp.br/ (2018)

\section{Quadro 3. Concordância para o item lexical sirva}

\begin{tabular}{|c|c|}
\hline Original & Tradução revisada \\
\hline $\begin{array}{l}\text { Deixe amornar por } 5 \text { minutos, coloque } \\
\text { numa tigelinha e sirva ou espere esfriar } \\
\text { e guarde num pote fechado por uns } 2 \\
\text { dias. }\end{array}$ & $\begin{array}{l}\text { Let cool for } 5 \text { minutes, transfer to a } \\
\text { small bowl and serve; or allow to cool } \\
\text { completely and store in an airtight } \\
\text { container for about } 2 \text { days. }\end{array}$ \\
\hline
\end{tabular}

Fonte: http://comet.fflch.usp.br/ (2018)

Em relação aos substantivos, foram selecionados cinco substantivos que servem, em algum nível, como medida dentro do meio culinário. $\mathrm{O}$ primeiro foi divido em dois grupos, combinando com outras palavras para formar as combinatórias:"colher de sopa" e "colher de chá".

A palavra "colher" é encontrada na vigésima quinta posição $\left(425^{a}\right)$ da lista, contando com 1262 aparições no CorTec e 489 ocorrências no CorTrad. A palavra "sopa" é encontrada na sétima posição ( $\left(7^{\mathrm{a}}\right)$, com 2540 aparições e 478 ocorrências. Por outro lado, a palavra "chá" é encontrada 
na oitava posição $\left(8^{\mathrm{a}}\right)$, com 2159 aparições e 334 ocorrências. No âmbito da tradução, há um consenso de para ambas as palavras: tablespoon para "colher de sopa" e teaspoon para "colher de chá" (quadro 4).

\section{Quadro 4. Concordância para o item lexical colher (de chá e de sopa)}

\begin{tabular}{|l|l|}
\hline \multicolumn{1}{|c|}{ Original } & \multicolumn{1}{|c|}{ Tradução revisada } \\
\hline 1 colher (sopa) de folhas de endro (dill) & 1 tablespoon minced onion \\
\hline $\begin{array}{l}1 \text { colher (chá) de capim-limão em } \\
\text { rodelinhas finas }\end{array}$ & 1 teaspoon thinly sliced lemongrass \\
\hline
\end{tabular}

Fonte: http://comet.fflch.usp.br/ (2018)

Em seguida, temos duas palavras que foram traduzidos como cups, sendo eles "copos" e "xícaras". A primeira se encontra na quadrigentésima trigésima segunda posição $\left(432^{a}\right)$, com 67 aparições e 40 ocorrências, contando as vezes em que é mencionada de forma genérica; sua forma no singular se encontra na centésima nona posição $\left(109^{\mathrm{a}}\right)$, com 320 aparições e 17 ocorrências. A segunda, por outro lado, se encontra na centésima terceira posição (103 $)$, 329 aparições e 272 ocorrências; assim como a primeira, esta também oferece sua forma no singular, que é encontrada na trigésima sexta posição $\left(36^{\mathrm{a}}\right)$, totalizando 1096 aparições e 879 ocorrências (quadro $5)$.

\section{Quadro 5. Concordância para o item lexical copos/xícaras}

\begin{tabular}{|l|l|}
\hline \multicolumn{1}{|c|}{ Original } & \multicolumn{1}{|c|}{ Tradução revisada } \\
\hline $\begin{array}{l}\text { Misture bem, coloque a salada } \\
\text { em copos ou potinhos individuais, } \\
\text { cubra com filme plástico e leve à } \\
\text { geladeira por pelo menos 1 hora, ou por } \\
\text { até 12 horas. }\end{array}$ & $\begin{array}{l}\text { Mix well, transfer to individual cups } \text { or } \\
\text { fowlm) and refrigerate for at least 1 hour, } \\
\text { or up to 12 hours. }\end{array}$ \\
\hline 1 xícara de suco de laranja & 1 cup fresh orange juice \\
\hline
\end{tabular}

Fonte: http://comet.fflch.usp.br/ (2018)

$\mathrm{Na}$ centésima quadragésima terceira posição $\left(143^{\mathrm{a}}\right)$, temos a palavra "pitada", com 242 aparições e 80 ocorrências; sua forma no plural se encontra trecentésima quadragésima sexta posição $\left(346^{a}\right)$, totalizando 87 aparições e 11 ocorrências. Como no caso do substantivo anterior, também 
A utilização do corpus de culinária da plataforma CoMET...

há um consenso de tradução de pitada, sendo ele pinch no singular e pinches no plural (quadro 6).

\section{Quadro 6. Concordância para o item lexical pitada}

\begin{tabular}{|l|l|}
\hline \multicolumn{1}{|c|}{ Original } & \multicolumn{1}{c|}{ Tradução revisada } \\
\hline 1 pitada de pimenta-do-reino & 1 pinch black pepper \\
\hline $\begin{array}{l}\text { Aqueça mais um fio de azeite, junte o } \\
\text { bacon e, quando começar a dourar, } \\
\text { acrescente a cebola, a cenoura, o salsão } \\
\text { e 1 pitada de sal. }\end{array}$ & $\begin{array}{l}\text { Heat a little more olive oil, add bacon } \\
\text { and, when it begins to brown, stir in } \\
\text { diced onion, carrot, celery, and a pinch } \\
\text { of salt. }\end{array}$ \\
\hline 2 pitadas de sal & 2 pinches salt \\
\hline $\begin{array}{l}\text { Junte metade do parmesão, pitadas de } \\
\text { noz-moscada e acerte o sal. }\end{array}$ & $\begin{array}{l}\text { Add half the Parmesan cheese, a few } \\
\text { pinches of nutmeg, and adjust salt. }\end{array}$ \\
\hline
\end{tabular}

Fonte: http://comet.fflch.usp.br/ (2018)

Notamos que a língua inglesa possui palavras bastante específicas, variando de acordo com o contexto; por outro lado, as medidas costumam ter apenas uma tradução. Esse contraste pode ser explicado pelo fato de os verbos, como mencionado acima, possivelmente serem traduzidos de formas diferentes por conta de uma questão cultural, enquanto que há a necessidade das medidas permanecerem as mesmas para um maior reconhecimento, até mesmo mundial.

\section{A elaboração das propostas de atividade lúdica}

Apresentamos, aqui, algumas das possíveis atividades que desenvolvemos com base nos dados de corpora. Primeiramente, o Scrabble, jogo de tabuleiro com 225 casas, dividas em 15 colunas e 15 fileiras. Entre essas 225 casas existem pontuações diferentes, as brancas são as com pontuação normal, enquanto as letras que forem adicionadas nas casas com coloração azul clara têm seu valor dobrado; já nas coloridas de azul escuro, essa pontuação triplica. Palavras que se formam nas casas cor de rosa valem o dobro, e as que estiverem nas vermelhas contam três vezes o valor normal. 
Figura 1. Exemplo do tabuleiro de Scrabble

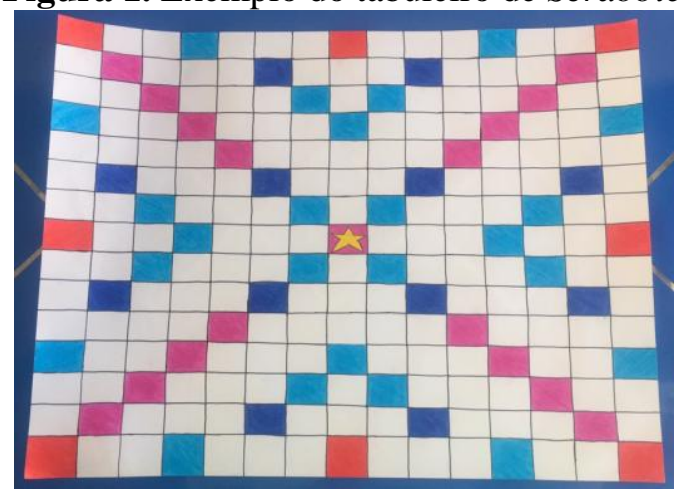

Fonte: Elaborado pelos autores (2018)

Ao contrário do jogo original, em que são permitidas todas as palavras do dicionário, nessa versão são aceitas apenas palavras que se relacionem com o tema escolhido - que no caso do nosso trabalho é o vocabulário gastronômico, mas que pode ser alterado para qualquer outro vocabulário específico que o professor desejar utilizar. O jogo segue até todas as peças terminarem, contudo, se todos os jogadores passarem a vez duas vezes seguidas o jogo acaba e aquele que tiver feito a maior pontuação vence.

A próxima atividade que apresentamos é a Imagem e ação. Nesse caso, os jogadores precisam se dividir em duas equipes com o mesmo número de integrantes. As equipes determinam qual delas começará jogando e qual dos integrantes será o primeiro a desenhar. O jogador puxa uma ficha da pilha, analisa rapidamente as palavras e a pontuação que cada uma delas oferece caso a equipe acerte e escolhe, por fim, uma para desenhar. Na sequência, ele deve fazer com que sua equipe adivinhe a palavra antes que o tempo da ampulheta se esgote (figuras 2 e 3 ).

Com as regras do jogo em mente, desenvolvemos algumas cartas com dez palavras selecionadas. Elas foram inspiradas no jogo oficial e possuem versão na língua portuguesa e na língua inglesa para que os jogares escolham em qual idioma preferem jogar. $O$ intuito é que, independentemente do idioma escolhido, os tradutores façam a tradução da palavra em algum momento e que, de alguma forma, sejam estimulados a fazê-lo com, por exemplo, acréscimo de ponto(s) ao realizar a tradução de forma correta. 
Figura 2. Exemplo de cartas de Imagem e ação com verbos em português

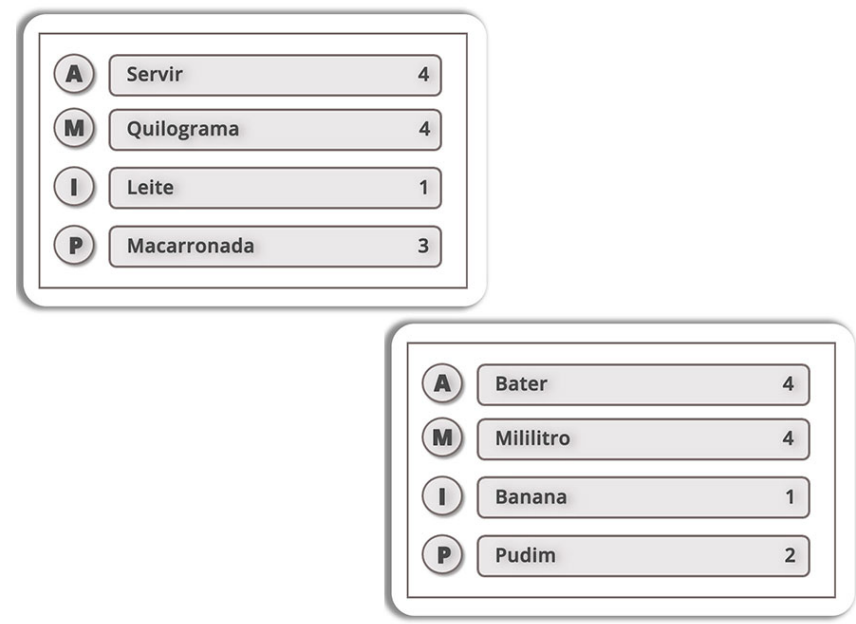

Fonte: Elaborado pelos autores (2018).

Como pode ser percebido ao observar a figura 2, cada carta possui quatro letras em sua lateral esquerda: $\mathrm{A}=$ ação, $\mathrm{M}=$ medida, $\mathrm{I}=$ ingrediente e $\mathrm{P}=$ prato. Em "ação", aparecem apenas verbos; em "medida", apenas medidas voltadas ao universo culinário; em "ingrediente", apenas um alimento; e, por último, aparece a combinatória de alimentos que seguem uma receita, resultando em "prato". Além disso, na frente de cada palavra temos uma numeração que varia de 1 a 6 de acordo com a dificuldade do desenho: quanto maior a dificuldade, maior seu valor.

A versão na língua inglesa (figura 3) possui poucas diferenças da sua versão em língua portuguesa, entre elas o "P" sendo trocado para " $\mathrm{D}$ ", de dish; as demais letras foram mantidas, sendo o $\mathrm{A}=$ action, $\mathrm{M}=$ measure e I = ingrediente. Além disso, alguns verbos nas fichas de substantivos não foram mantidos com a mudança de idioma. A alteração, no entanto, não teve outra razão além de uma questão estilística. 
Figura 3. Exemplo de cartas de Imagem e ação com verbos em inglês

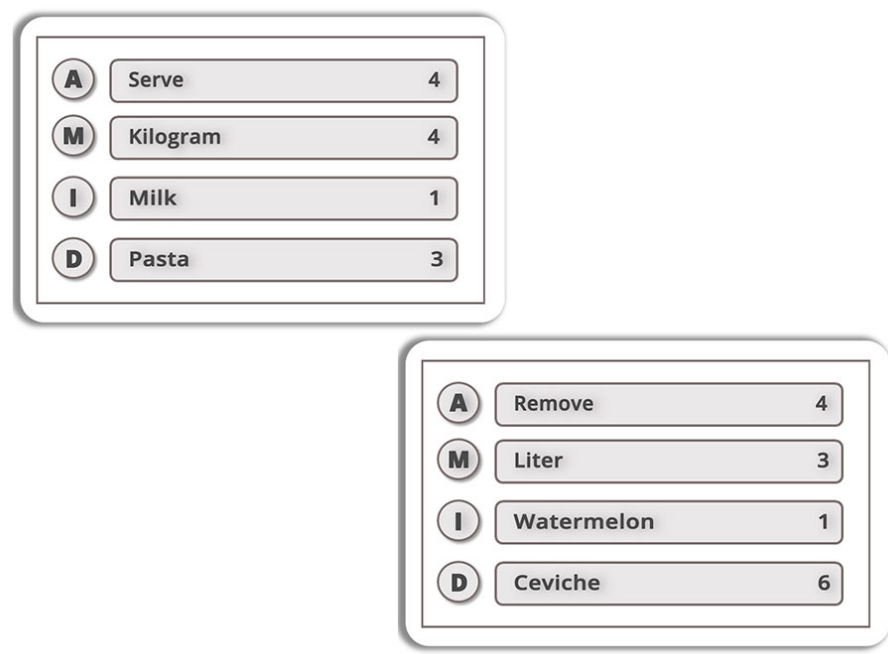

Fonte: Elaborado pelos autores (2018).

\section{Considerações finais}

Este trabalho nos possibilitou entender que a LC mostra-se um importante instrumento que, além de ser reconhecido como parte essencial na formação das competências de aprendizes de Tradução, associa-se às demais habilidades sugeridas pelos pesquisadores como uma base teóricometodológica que os ampara na busca por saberes linguísticos, extralinguísticos, etc.

Tendo em vista que, assim como afirma Massa (2015), a educação lúdica integra mente e corpo, sentimento e razão, e é mais do que apenas um recurso formativo, mas também uma possibilidade de autodesenvolvimento; foram elaborados jogos para auxiliar o desenvolvimento de saberes tradutórios em alunos dos anos iniciais da formação de tradutores. As brincadeiras, elaboradas de acordo com as normas pré-estabelecidas e adequadas ao conjunto vocabular da culinária, favorecem a negociação de estratégias e permitem aos aprendizes lidarem com diferentes habilidades. 
A frequência das palavras no subcorpus do CoMET permite traçar uma relação direta com as regras dos jogos escolhidos para as atividades didáticas, uma vez que ambos conduzem a formas de negociação e autonomia, comumente consideradas necessárias em uma formação profissional do tradutor, principalmente no que diz respeito aos elementos extralinguísticos e comunicativos de sua atuação.

Scrabble e Imagem e ação, entre os jogos de palavras, permitem valorar a frequência de uso, bem como socializar os resultados das escolhas tradutórias, atribuindo a elas uma pontuação e tornando o processo de aquisição de saberes tradutórios mais prazeroso, além de extravasar os limites do subcorpus do CoMET e aumentar a interação com novos dados linguísticos e culturais.

Dessa forma, as interações a que nos propomos no decorrer desse trabalho são ilustrações de algumas das possibilidades de atividades das quais podemos fazer uso, visto que o leque de possibilidades é muito maior e deve ser usufruído em sua totalidade, ampliando as relações interdisciplinares entre corpora e ensino de competências, bem como permitindo um diálogo com teorias pedagógicas aplicadas de maneira efetiva por pesquisadores como Libâneo (2005) e D’Ávila (2007).

\section{Referências}

ALMEIDA, P. N. Educação lúdica: teorias e práticas. São Paulo: Loyola, 2006.

ALVES, F.; MAGALHÃES, C.; PAGANO, A. Traduzir com autonomia: estratégias para o tradutor em formação. São Paulo: Contexto, 2003.

ALVES, F.; TAGNIN, S. E. O. Corpora e ensino de tradução: o papel do automonitoramento e da conscientização cognitivo-discursiva no processo de aprendizagem de tradutores novatos. In: VIANA, V.; TAGNIN, S. (Org.) Corpora no ensino de línguas estrangeiras. São Paulo: HUB Editorial, 2010. p. 189-203.

BAKER, M. Towards a methodology for investigating the style of a literary translator. Target. International Journal of Translation Studies, v. 12, n. 2, p. 241-266, 2000. 
BERBER SARDINHA, T. Linguística de Corpus. Barueri, SP: Manole, 2004.

- Como usar a Linguística de Corpus no ensino de língua estrangeira-por uma Linguística de Corpus Educacional brasileira. In: VIANA, V.; TAGNIN, S. (Org.) Corpora no ensino de línguas estrangeiras. São Paulo: HUB Editorial, 2010. p. 293-348.

BOWKER, L. A Corpus-based approach to evaluating student translations. The Translator, v. 6, 2000. p. 183-210.

DAYRELL, C. O uso de corpora para o estudo da tradução: objetivos e pressupostos. Tradução em Revista. Fascículo especial, Rio de Janeiro, p. 87-102, 2015.

D’ÁVILA MAHEU, C. Eclipse do lúdico. IN: D’ÁVILA MAHEU, C.(Org.). Educação e ludicidade: ensaios 04. Salvador: Universidade Federal da Bahia, Faculdade de Educação, Gepel, 2007. p. 11-20.

DIAS, I. S. Competências em Educação: conceito e significado pedagógico. Revista Semestral da Associação Brasileira de Psicologia Escolar e Educacional, São Paulo, v. 14. n. 1, p. 73-78, jan/jun 2010.

GUTIÉRREZ, L. P. Fundamentos de la traducción pedagógica: traducción, pedagogía y comunicación. Sendebar, v. 23, p. 321-353, 2012.

HURTADO ALBIR, A. La competencia traductora y su adquisición: un modelo holístico y dinámico. Perspectives: Studies in Translatology, v. 7, n. 2, p. 177-188, 2000.

LAVIOSA, S. Corpus-based translation studies: theory, findings, applications. Roma: Rodopi, 2002.

LIBÂNEO, J.C. As teorias pedagógicas modernas revisitadas pelo debate contemporâneo na educação. IN: LIBÂNEO, J. C.; SANTOS, A. (Org.). Educação na era do conhecimento em rede e transdisciplinaridade. Campinas, SP: Editora Alínea, 2005. 
A utilização do corpus de culinária da plataforma CoMET...

MARTINS, M. A. P. Novos desafios na formação de tradutores. Cadernos de Tradução, v. 1, n. 17, p. 25-44, 2006.

MASSA, M. S. Ludicidade: da etimologia da palavra à complexidade do conceito. Aprender: Caderno de Filosofia e Psicologia da Educação, Vitória da Conquista, Ano IX, n. 15, p.111-130, 2015. Disponível em <http://periodicos.uesb.br/index.php/aprender/article/view/5485>. Acesso em: 24 fev. 2017.

MORELLI, M. Reflexiones sobre la traducción: problemáticas y retos. Signos Lingüísticos, v. 4, n. 1, p. 75-92, jan/jun 2008.

O'KEEFFE, A.; MCCARTHY, M. Historical perspective: what are corpora and how have they evolved?. IN:__. The Routledge handbook of corpus linguistics. London: Routledge, 2010. p. 3-13.

OLIVEIRA, L. P. Linguística de Corpus: teoria, interfaces e aplicações. Matraga, v. 16, Rio de Janeiro, p. 48-76, 2009.

OLOHAN, M. Introducing corpora in translation studies. London: Routledge, 2004.

PACTE. Results of PACTE's experimental research on the acquisition of translation competence: the acquisition of declarative and procedural knowledge in translation: the dynamic translation index. Translation Spaces, v. 4, n. 1, p. 29-53, 2015.

- ${ }^{-}$. First results of PACTE group's experimental research on translation competence acquisition: the acquisition of declarative knowledge of translation. MonTI: Monografías de Traducción e Interpretación, v.especial 1,p. 85-115, 2014.

. Results of the validation of the PACTE Translation Competence Model: translation problems and translation competence. In: ALVSTAD, C.; HILD, A.; TISELIUS, E. (Eds.) Methods and strategies of process research: integrative approaches in translation studies. Amsterdam: John Benjamins, 2011a. p. 317-343. 
. Results of the validation of the PACTE Translation Competence Model: translation project and dynamic translation index. In: O'BRIEN,S. (Ed.) Cognitive explorations of translation, Londres \& Nueva York: Continuum Studies in Translation, 2011b. p. 30-53.

. La competencia traductora y su adquisición", Quaderns. Revista de Traducció, n. 6, p. 39-45, 2001.

PICCIONI, S.; PONTRANDOLFO, G. Competencia traductora y recursos informáticos: por qué las tecnologías no sustituyen la formación en traducción. Revista de Lingüística y Lenguas Aplicadas, v. 12, p. 87-101, 2017.

SERPA, T.; ROCHA, C. F. Tomando uma obra infantojuvenil traduzida para o português e o espanhol como subsídio para o ensino da tradução. Revista do GEL, v. 13, p. 91-117, 2016.

. Os estudos de corpora na tradução em diálogo com a sociologia da educação: formação de um habitus tradutório com subsídios de brasileirismos das obras de Darcy Ribeiro. 2017. Tese (Doutorado em Estudos Linguísticos) - Instituto de Biociências, Letras e Ciências Exatas da Universidade Estadual Paulista "Júlio de Mesquita Filho", Campus de São José do Rio Preto, 2017.

Recebido em: 02/01/2019

Aceito em: 08/02/2019

Title: The use of a corpus of texts about cooking from Project CoMET as a basis for the creation of ludic pedagogical activities to teach translational competences 